OPEN ACCESS

Edited by:

Rob Cassidy,

Concordia University, Canada

Reviewed by:

Yotam Hod,

University of Haifa, Israel

Tracey Birdwell,

Indiana University, United States

*Correspondence:

Bruno Poellhuber

bruno.poellhuber@umontreal.ca

Specialty section:

This article was submitted to

Digital Education,

a section of the journal

Frontiers in ICT

Received: 30 November 2017

Accepted: 23 April 2018

Published: 17 May 2018

Citation:

Poellhuber B, Fournier St-Laurent S and Roy N (2018) Using the TAM and

Functional Analysis to Predict the

Most Used Functions of an Active

Learning Classroom (ALC).

Front. ICT 5:8

doi: 10.3389/fict.2018.00008

\section{Using the TAM and Functional Analysis to Predict the Most Used Functions of an Active Learning Classroom (ALC)}

\author{
Bruno Poellhuber ${ }^{1 *}$, Samuel Fournier St-Laurent ${ }^{2}$ and Normand Roy ${ }^{1}$ \\ ${ }^{1}$ Department of Psychopedagogy and Andragogy, Université de Montréal, Montréal, QC, Canada, ${ }^{2}$ Learning Support and \\ Pedagogical Development service, Collège Ahuntsic, Montréal, QC, Canada
}

Since the pedagogical reform undertaken in the field of physics teaching with the SCALE-UP project, research has shown that active learning classrooms (ALC) can lead to substantial gains. The reflection on ALC is now burgeoning, with this area being the number-one focus of university technological investments in 2017. However, even though a kind of ALC standard has emerged (teacher pod at the center of the room, round tables, a projector for each table, etc.), very few researchers actually investigate the precise layout of ALCs and which particular features are the most important from the students' perspective. This is precisely what this study aims to do, relying on the TAM (Technological Adoption Model). The study took place in three colleges in Quebec with ALCs, using a functional analysis approach. In this process, nine functions were identified. A single-item questionnaire was developed around a modified TAM (including interest) and sent to 352 students who rated the frequency of use, utility, interest and ease of use of each of the nine functions. Qualitative data were collected through group interviews with students. Average scores were computed for each construct with the nine functions and they showed satisfactory consistency. Automated text analyses were conducted on the answers to the open-ended question. The results show that from the students' perspective, the most important functions are related to features that facilitate group work (having a team table and using wall surfaces that can support image projections and annotations). Being able to use computers supplied by the college, connect student-owned devices to the team projector and annotate projection surfaces also ranked high. The correlation between frequency of use, interest, utility and ease of use is high and statistically significant. The qualitative data show that having comfortable, movable chairs is also important. The special look and feel of an ALC also seem to make students more comfortable. On a less positive side, some students indicate that visual obstruction is an obstacle in the periods when the teachers lecture in the class. These results may support cost-effective ALC design.

Keywords: TAM, functional analysis, ALC, active learning classrooms, students, classroom layout 


\section{INTRODUCTION}

The reflection on active learning classrooms (ALC) is burgeoning, but few researchers investigate how to lay out these learning spaces and which particular functions are the most important from the students' perspective. This is precisely what this study aims to do, relying on the TAM (technological adoption model) and a functional analysis approach. From a professor's point of view, it is fairly obvious that a classroom's layout influences the type of pedagogy that can take place in it, facilitating some types and rendering others more difficult: lectures fit perfectly in lecture halls, but cooperative pedagogy is harder to achieve. According to Wesch (2007), a well-known physical anthropologist, the layout of our teaching and learning spaces says a lot about the way we conceive of teaching and learning. The set-up of very large lectures halls common in all North-American universities is such that students are seated very close together. The presenter (professor) stands on the stage, often on a podium which is sometimes next to a large screen for projections. All seats are oriented toward the front and the rows are designed to focus attention toward the front screen and the presenter. Participants in the audience ("students") have little or no room for anything other than a notebook. This set-up implicitly but very clearly communicates a vision that the information will come from an expert who is on the stage, who is worthy of the participants' attention and who will "profess" so they can take notes.

\section{PROBLEM}

This very transmissive approach has been challenged in the STEM reform movement in relation to concerns regarding student retention and learning in STEM areas. In 1998, Hake ran a study on 6542 students registered in 62 introductory physics courses, using the Force Concept Inventory (Hestenes et al., 1992) to compare conceptual gains between an "active engagement" condition and a traditional lecture approach. Conceptual gains proved to be significantly higher in the "active engagement" condition (Hake, 1998).

Following these results, the original SCALE-UP project objectives were to improve student learning and attitudes, design "new modes of instruction for large enrolment sections" and develop teaching guides and instructional materials (Beichner and Saul, 1999), but the SCALE-UP project became famous because it was a pioneer in experimenting with classroom layout. It proposed new ways of exploring large classroom layouts to facilitate active learning and collaboration in technology-rich environments. As stated by its originator in an early article, "the primary goal of the SCALE-UP Project is to establish a highly collaborative, hands-on, computer-rich, interactive learning environment in large-enrolment physics courses. We know from extensive educational research that students should collaborate on interesting tasks and be actively involved with the material they are learning" (Beichner and Saul, 1999).

Within a few years, the SCALE-UP project gained speed, and in 2006, about two dozen universities had climbed aboard (Beichner et al., 2007). Over a decade later, over 250 sites inspired by SCALE-UP were in operation in the US, and more than 31 are located in the province of Quebec (Canada). This rapid expansion gave birth to deep, new reflections on how to lay out learning spaces with technology in order to facilitate active learning and collaboration supported by technology. It created a focus on the complex relations between classroom layout, technology, pedagogy and learning in different types of spaces. A project report on the SCALE-UP documented the many advantages of the SCALE-UP model over traditional lectures in lecture halls in introductory physics courses: better conceptual understanding, better course attendance, lower failure rates (better retention), better problem-solving skills (Beichner et al., 2007).

Emerging from a specific SCALE-UP subproject, the TEAL (technology-enhanced active learning) project at MIT was implemented in all MIT introductory physic instructions. "Technology-enabled active learning is a teaching format that merges lectures, simulations, and hands-on desktop experiments to create a rich collaborative learning experience" (http:// icampus.mit.edu/projects/teal/). The TEAL project went further in the technology enrichment aspect of the pedagogical project, including simulations, visualizations and hands-on experiments in the collaborative learning approach. Both SCALE-UP and TEAL aimed not only to redesign classrooms, but also to redesign instruction, the way the introductory courses were taught, the teachers' roles and the instructional materials. The TEAL project generated conceptual gains similar to those obtained in the SCALE-UP set-up (Dori et al., 2003). Researchers in Quebec replicated these results a few years later (Charles et al., 2011).

In short, in the field of physics teaching, research shows that the student-centered pedagogy used in active learning classes has led to greater conceptual gains than those made with traditional methods (Hake, 1998; Dori et al., 2003; Beichner et al., 2007; Charles et al., 2011), as well as other interesting gains such as lower failure rates (Dori et al., 2003) and better class attendance (Beichner et al., 2007). In these early studies, profound pedagogical changes accompanied the physical changes. From the teacher-student transmission of the material to the student-student interactions with the material that take place in this new environment, many changes are needed. The SCALE-UP report (Beichner et al., 2007) mention of the challenges of course design. Instructional design in this context takes more time than preparing lectures. The design must also take into account the need for students to work in groups and stay engaged in their tasks. The skills required for lecturing are also different from those required to offer adequate cognitive and metacognitive support for the students.

Meanwhile, the evolution of learning technologies, the emergence of low-cost high-performance laptop computers and the birth of the iPad led to an increase in one-to-one initiatives (Bocconi et al., 2013) and brought BYOD (bring your own device) to the fore. BYOD was deemed to be the most important development in educational technology in the 2015 Horizon report (Adams Becker et al., 2017). The advent of BYOD creates a need for accommodation. For example, "University of Scranton leaders assert that BYOD policies will also impact the physical environment of the classroom, and that rigid furniture should 
be replaced with more flexible workspaces to accommodate the collaboration that mobile apps and other features promote" (Adams Becker et al., 2017, p. 38).

While in the SCALE-UP and TEAL spaces, pedagogy and layout are intertwined in various and complex ways, a recent line of research initiated at the OIT of the University of Minnesota turned its focus on the specific role of classroom layout, using quasi-experimental designs to isolate the classroom factor from the others. Brooks (2011) ran an initial quasi-experimental study in a biology course, keeping all variables constant except for the physical layout of the classrooms. Both sections of the course had the same instructor, were offered in the same time slot (on different days) and relied on the same course material and instructional approach. The students in the active learning classroom (ALC), which had significantly lower ACT scores compared to the students in the traditional classroom, performed as well as them and had the same final grades. These findings suggest that "physical space alone can improve student learning" (Brooks, 2011, p. 725). In a replication of this study with a different instructor in another biology course (Cotner et al., 2013), similar results were obtained.

In a further study, Brooks (2012) used another quasiexperimental design to compare teacher and student behaviors in two sections of the same course, using a systematic behavioral codification grid. This study showed that the classroom layout actually has an effect on the behavior and pedagogy of the instructor. The instructor gave significantly more lectures and significantly fewer group activities in the traditional classroom than in the ALC. In this study, both lectures and team work were linked with student engagement, as measured by the observation of "on task" behaviors. This particular study suggests that room layout does have an impact on the type of pedagogy, a result also obtained by Whiteside et al. (2010), and that both types of pedagogy can lead to on-task behaviors.

In a quasi-experimental ex post facto longitudinal study, Brooks and Solheim (2014) focused on the impact of the pedagogical transformation of a finance course taught in an ALC, supported by a faculty development program. The authors report significant differences in student participation, as well as student grades (for individual assignments and final grades). Other results suggest that it is the active learning pedagogy that is effective in the SCALE-UP project (see Soneral and Wyse, 2017, as well as Stoltzfus and Libarkin, 2016).

There are intricate links between pedagogy, room layout, technology and student outcomes. Whether changes in classroom layouts produce a direct effect on pedagogy is subject to debate, but it does seem that room layout induces or facilitates particular pedagogical approaches and that the greater part of the gains obtained in projects such as SCALE-UP come from the pedagogy rather than from the room layout.

For some, changes in classroom layouts and pedagogical changes should take place simultaneously (Woolner et al., 2012). For example, it seems that teacher-centered approaches are actually less effective in active learning classrooms (Charles et al., 2011). In the context of technology-rich learning spaces, it is also useful to point out that changes in pedagogy are also necessary to effectively use technology (Basque, 2004; Barrette, 2009).
Since the SCALE-UP started, many universities and colleges have picked up the concept and Active Learning Classrooms (ALC) have become somehow standardized, even though there are many variations on the theme. In an ALC, the instructor podium is located in the center of the room, in order to balance interactions with the different student teams. Other features usually found in an ALC are:

- tables for teams of 6 to 8 students (typically round or oval)

- chairs on wheels

- work surfaces on walls such as a projector and wall screen for each team

- a technology-rich environment that provides laptops, computers or tablets to the students, as well as various software programs

The concept of flexibility is now emerging in the literature, usually with the design of flexible learning spaces. For example, at Calgary's Taylor Centre, learning studios, team tables, chairs and even the instructor podium and team projectors are designed to be mobile.

Reflections and experiments with other types of learning spaces are expanding, and we can now see examples of active lecture halls or active labs. McGill University has experimented with these and even set up an active wet lab equipped with advanced biochemistry and chemistry laboratory apparatuses (https://www.mcgill.ca/tls/spaces/classrooms/). The focus is currently also shifting to the learning potential of spaces other than classrooms, and to the student perspective on informal learning spaces such as halls, cafeteria, library spaces, etc. Vo (2015) investigated the factors behind college students' choices of informal learning spaces. Carnell (2017) also focused on informal learning spaces, drawing design principles from students and staff interviews.

While we see many new types of active or flexible learning spaces, few studies actually document how traditional ALC are used (Wilson and Cotgrave, 2016). Research has focused mostly on the teachers' pedagogies in these spaces, and the students' perspective on these spaces has not frequently been taken into consideration. This tendency to focus on faculty perceptions and practices is not consistent with the student-centered practices that are the target of the ALC. The instructors have to design active learning scenarios for these environments, which are usually much more student-centered, and they have more choices than in the more traditional pedagogical scenario. This generally gives them a lot of freedom in the choices of the particular ALC features they will use during team work. Some of the research with students has focused on the choices they make in their personal study spaces (see for example Alphonse-Prescott, 2016) or personal learning environments (Roland and Talbot, 2015).

Very little research has been done on how teachers or students actually use the different features of an ALC and which features are the most important in the design phase. Benoit (2017) is a notable exception. He interviewed both students and instructors on their perceptions of two types of ALC layout on three topics; equipment and technology, learning environment design and interaction. He found that rooms resembling classical ALC layout were more conducive to student-student interactions 


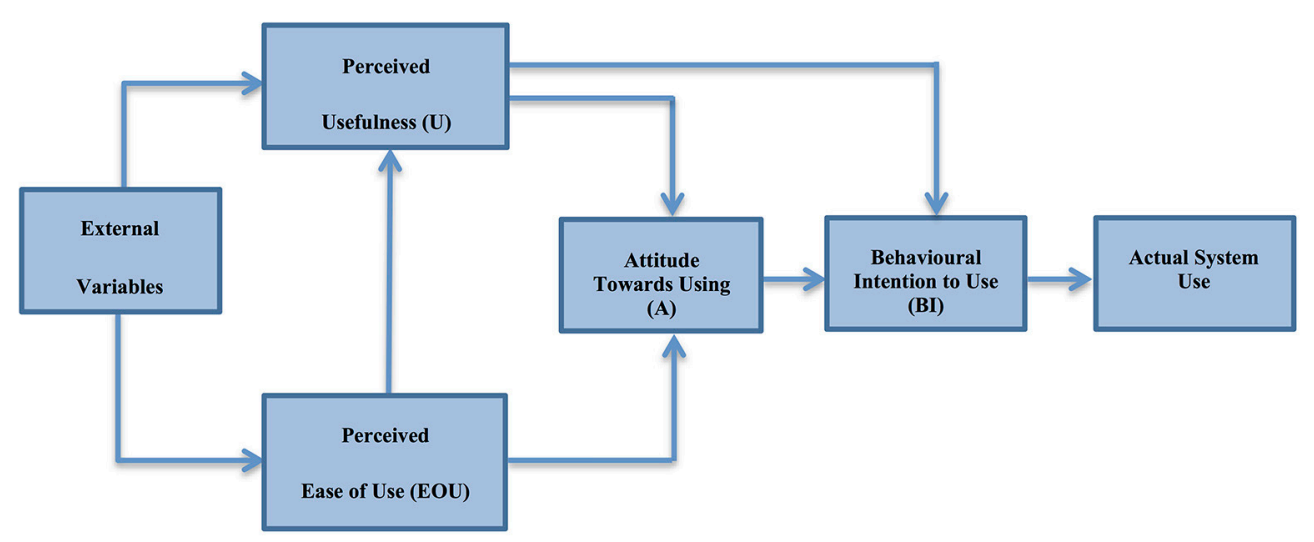

FIGURE 1 | The original TAM (from Davis et al., 1989, p. 985).

and group work, as well as student-instructor interaction. These rooms were also perceived to be more welcoming and more comfortable. Portable whiteboards were the most used technological feature. Concerns about table size and stability were identified.

The costs of setting up an ALC can be quite high, from $\$ 100,000$ (University of West Florida, 1999) to even $\$ 465,000$ (McGill Teaching and Learning Services, 2009). Considering the relatively high cost of designing and implementing active learning spaces, identifying crucial aspects of ALC layout is particularly important. In a low-tech SCALE-UP mock-up project, results similar to the original SCALE-UP research were obtained, which suggests that the most expensive technological features of an ALC might not be the most important (Soneral and Wyse, 2017).

The objective of this study is to evaluate the most important functions in the layout and technological choices for active classrooms.

\section{THEORETICAL FRAMEWORK}

In order to understand the choices made by student teams to use (or adopt) any particular function, we decided to rely on the technology acceptance model (TAM), because of its simplicity, its applicability to the particular context and its efficiency in predicting the adoption of particular technologies in educational settings (see Figure 1).

The TAM has been developed to explain and predict the adoption of technological systems by users, specifically, computer use and software applications. Davis et al. (1989) developed the TAM from the theory of reasoned action (TRA). The TRA predicts the intention to adopt behavior based on a person's beliefs and attitudes. This focus on behavioral intent was incorporated into the TAM to predict the adoption of computers or software. A comparison between the two models revealed a stronger predictive power for the TAM than the TRA between the intention indicators and the actual use of word processing software (Davis et al., 1989).
The TAM has been widely used in research on technology adoption and is one of the most cited models in the literature. It is a simple and effective model for predicting the intention to adopt a technology.

In developing the TAM, Davis (1989) wanted to build better measures for predicting and explaining the use of various technological environments, particularly computer applications. According to the TAM, the intent to use a technological environment such as a computer application depends essentially on its perceived usefulness - "the degree to which a person believes that using a particular system would enhance his or her job performance" (Davis, 1989, p. 320)-and perceived ease of use-"the degree to which a person believes that using a particular system would be free of effort" (Davis, 1989, p. 320).

In this project, we used the TAM in an unusual way. First, we wanted to focus on the adoption of each of the particular functions of an active classroom, rather than look at the adoption of the ALC as a whole, based on the premise that particular ALC functions differ in their usefulness and ease of use. Second, rather than trying to predict actual use from the intent to use (as the TAM is generally used), we had the opportunity to measure adoption through actual use. As done by Ha et al. (2007), McGowan et al. (2012) and others, we proposed to consider the frequency of use of each of the different functions as an indicator of adoption and actual use. The TAM model suggests that the functions perceived as the most useful and the easiest to use would be the most adopted and, hence, the most frequently used. We also proposed to identify the most useful and easiest functions from the point of view of the students, rather than the instructors. Relationships can be established between the TAM and general expectancy-value models of motivation. Perceived usefulness is part of the task value component in the Pintrich model, which also includes intrinsic goals and affects (Pintrich, 2003). We can also pinpoint some conceptual resemblance or at least a relationship between perceived usefulness and selfefficacy. Venkatesh and Davis (1996) actually linked self-efficacy and usability to perceived usefulness. In Eccles's motivational model, interest is part of the task value component (Eccles and Wigfield, 2002). In a previous study, Poellhuber et al. (2013) 
showed that interest was a stronger predictor of the adoption of a social networking system than usefulness. This study therefore relies on a modified TAM that focuses on interest in the use of a particular function.

\section{METHODS}

This exploratory study relies on the pedagogical value analysis developed by Rocque et al. (1998) and used in other educational contexts (Severin, 2009). This approach adapts the value analysis and functional analysis approach widely used in engineering in order to apply it to educational contexts and developments. It has been frequently used in Quebec to develop innovative products or services aimed at student clienteles with particular needs (see, for example, Chalgoumi, 2011). This approach is deployed in three phases: pre-design, functional analysis and development. The pre-design phase draws on a user needs analysis and on what is actually known in the field, for example, from the scientific literature. It can also be based on a comparative analysis of existing products or services that meet similar needs. In the functional analysis phase, the focus is on the functions that the particular product has to fulfill, while leaving room for creativity on how each particular function can be filled (Rocque et al., 1998). Finally, the development phase is in the hands of developers who develop a prototype based on the identified functions, but keep some freedom in the design.

\section{Context}

This particular study is part of a large research project on the conditions of effectiveness of ALC, in which 19 teachers from five Quebec cégeps (junior colleges in the US and Canada) partnered with a university researcher in a design-based study that investigated the conditions of pedagogical practices that were the most conducive to student motivation and engagement. The project started in the winter semester of 2014 and continued until the fall semester 2015. Teacher participation varied from one semester to another, some being in the project for only one semester (not necessarily the first) and others participating for all four semesters. The study focused mainly on the effect of pedagogical practices and conceptions, as well as innovation adoption (St-Laurent et al., 2017) and pedagogical change over time (Fournier St-Laurent and Poellhuber, submitted). The main focus of the project was the pedagogy in the ALC. Early advantages reported by ALC students pertained the pedagogical approaches, technology, collaboration and team productivity and, finally, the classroom layout itself (Poellhuber et al., 2018).

An iterative design-based research (DBR) approach was adopted as the general methodological framework (Brown, 1992). DBR is particularly useful for studies seeking to make both a contribution to theoretical knowledge and usable knowledge applicable to authentic learning situations (Collins et al., 2004; Anderson, 2005). In this study, the researchers and teachers had many opportunities to meet, discuss and work together to develop the learning scenarios to be implemented in the ALC and to interpret the qualitative and quantitative data collected during the project. The instructors were offered training sessions in the ALC to model cooperative scripts, ways to enhance student motivation and engagement, the development of pedagogical scenarios and teamwork management. The teachers were given ample time to discuss both their successes and their failures. This led to a wide variety of the actual scenarios, which were implemented in the ALC.

At the outset of the project, three of the participating colleges did not yet have an ALC and needed to find an effective approach to ALC design. Considering the cost constraints, ALC design came up as a problem that needed to be solved before pedagogical integration could take place. The Cégep regional de Lanaudière in Terrebonne was the last cégep to design its own classroom, and it benefited from the other colleges' designs and from Collège Ahuntic's functional analysis process. College Ahuntsic used a functional analysis approach to design its own ALC, with a project team made up of one educational developer, three teachers and one IT administrator. Using both a literature review and a comparative analysis of existing active learning classrooms (with visits to many ALC spaces), the committee conducted a functional analysis of three particular functions: utility functions, constraint functions and esteem functions. Briefly, utility functions are the main features of a product, which make it useful (e.g., interactive whiteboards can facilitate interaction with digital documents). Constraint functions refer to design limits (e.g., the object may not weigh more than $10 \mathrm{~g}$ ). Esteem functions are those that make the product attractive (e.g., shiny stickers on a phone). The results of the process at that college were shared with the other participating colleges that were planning to design an ALC.

\section{Sample}

Nine teachers from three of the colleges participated at the last semester of the research (fall, 2015). They were teaching in four subjects (physics, French, biology and philosophy) and the particular pedagogical practices deployed in the ALC varied greatly from one teacher to another. A total of 337 of their students answered a midterm questionnaire that had a TAM section on the various functions of their ALC. Of these, 252 answered the TAM part of the questionnaire at the end of the survey.

\section{Data Collection}

In this particular case, the location of each ALC supplied many of the constraint functions. College Ahuntsic's committee focused on the utility functions while respecting the identified constraints. It identified nine utility functions that are particularly important in an ALC:

1. Having a team table

2. Using wall surfaces that can support image projections and annotations

3. Using computers supplied by the institution

4. Using tablets supplied by the institution

5. Connecting computers, tablets or other student-owned devices to the team projector

6. Sharing the work of a particular team with the other teams

7. Annotating projection surfaces while working in teams

8. Capturing an image of the work on the team's work surface 


\section{Capturing and sharing the image of a page or a real object}

Each of these functions can be accomplished by a variety of means, which vary widely in cost. For example, functions 2, 7 and 9 can be accomplished by a set-up in which each team has access to a team smartboard (which is the case at Dawson College, in Montréal) for an approximate cost of about $\$ 35,000$. It can also be accomplished by low-tech whiteboards that serve as a surface for regular projectors. Annotations can then be made on the projections with dry erase pens and the students can take screen captures with their smartphones, for an approximate cost of about $\$ 7,500$.

This procedure departs from the use of the validated questionnaire developed by Davis comprising four items per subscale, but due to the innovative approach of the modified TAM, the decision was made to use a single-item scale. Wanous et al. (1997) suggest that in particular situational constraints, single-item scales can be as robust as a well-constructed scale. Many studies have demonstrated the reliability of the single-item scale (see Hoeppner et al., 2011; Leung and Xu, 2013). For the purpose of this study, a full scale would dramatically increase the length of the situational questionnaire (nine utility functions by three variables by four items). Each of the nine functions were listed in a table, and for each one of these, students had to rate the frequency of use on a five-point Likert scale, as well as interest (from not at all interesting to highly interesting), utility (from not at all useful to highly useful) and ease of use (from not easy at all to really easy) on a seven-point Likert scales.

To support the single-item questionnaire, one open-ended question asked them whether any other function was important: Are there other functions available in this classroom (e.g., furniture, tools, software) that have helped make this course motivating?

Thirteen semi-structured student group interviews took place during the last semester of the project around several themes, including the physical layout of the ALC. The nine participating teachers in the three colleges were also interviewed. In the interviews, the teachers were invited to comment qualitatively on the importance of these functions and to describe how they would actually be used. Usefulness, interest and ease of use scores were computed, as well as a global modified TAM score.

\section{Analysis}

In order to understand the most important functions in the layout and technological choices in active classrooms, we used descriptive analysis for the single-item questionnaire. We used composite items to evaluate the relationships among the constructs. Average scores were computed for each construct with the nine functions and they showed satisfactory consistencies, based on Cronbach's alpha (Frequency of use $=0.72$; Interest $=0.84$; Usefulness $=0.84$; Ease of Use $=0.79$ ). Automated text analyses were conducted on the 99 answers to the open-ended question in the Survey Monkey text analysis machine and revised manually by one coder.

All interviews were audio recorded, transcribed and coded using the QDA Miner qualitative analysis software. The coding grid was developed using a mixed approach relying both on pre-existing categories based on our conceptual framework and on emerging categories (Miles et al., 2013). The coding grid was developed by one researcher and one assistant consensually coding three student interviews. The final coding grid includes 48 codes grouped in nine categories. After stabilization, the coding grid was used independently by both coders on three interviews. Final interjudge agreement on these was $88.7 \%$. Reports were generated on codes and excerpts pertaining to the physical layout of the ALC. A second stage of analysis then took place in order to identify the subjects most frequently discussed concerning classroom layouts. Significant excerpts in relation to the particular functions of an ALC were identified.

\section{Ethics}

The project was conducted under an ethics certificate from the Université de Montréal's pluridisciplinary ethics committee (CPER-13-112-D) and from each of the colleges with participating teachers. This study was carried out in accordance with its recommendations with informed consent from all subjects, including those participating in focus groups. All subjects were met by the researchers and gave written informed consent in accordance with the three Canadian Tri-Council guidelines, for both the survey and the group interviews.

\section{RESULTS}

In this section, descriptive statistics on the different components of the TAM will be reported first, followed by a correlation table of the TAM sub-scores. The main categories that emerged from the qualitative analysis will then be presented.

Frequency of use roughly represents the level of effective adoption of each function. We can see from Figure 2 that the team table is by far the function most frequently used by students in the ALC. The other most frequently used functions are wall surfaces (boards), computers supplied by the school, annotations and screen sharing. Real object images and captures are the most rarely used or adopted, with a rating of "rarely" for captures and "never" for tablets supplied by the institution.

Table 1 represents the mean of the interest, utility and ease of use questions for each of the nine functions. It is in descending order by perceived utility, but the order remains the same for perceived interest. If the list is reordered by perceived ease of use, wall boards move to the first place, and the rest of the list remains unchanged.

In the TAM, studies usually show correlation between perceived usefulness, perceived ease of use and attitude. Based on the general composite score, we confirmed the hypothesis that these concepts are highly correlated (Table 2), although frequency of use is less correlated with the other concepts.

Automated text analysis shows that chairs, and, more precisely, comfortable chairs on wheels, are an important function omitted from the list (Figure 3). It was mentioned by 16 students. The relevance of the use of specialized subject-specific applications by teachers (such as Maple or 


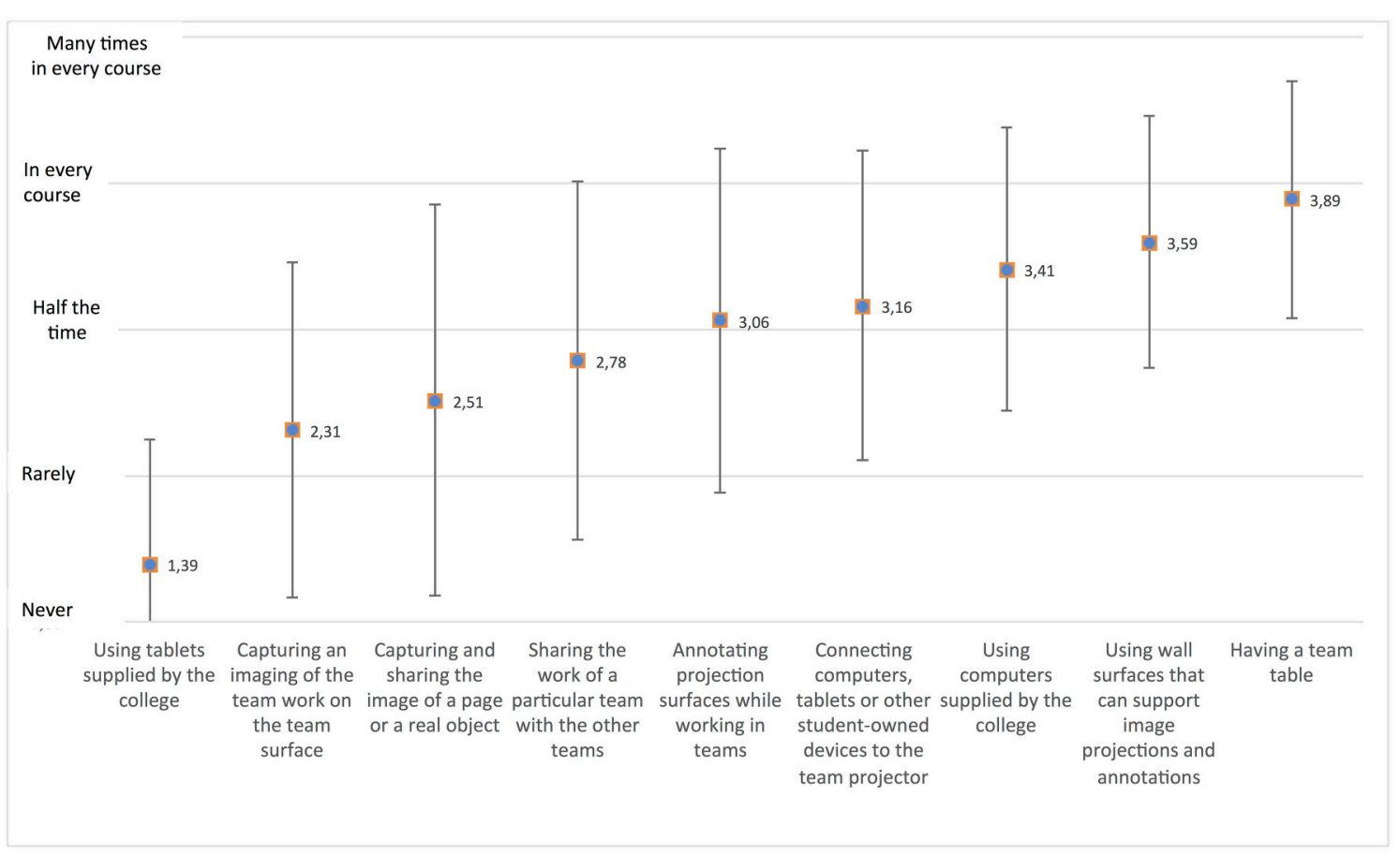

FIGURE 2 | Answer distribution for the frequency of use of the nine different functions.

TABLE 1 | Interest, utility and ease of use means for each function.

\begin{tabular}{|c|c|c|c|}
\hline & Interest & Utility & Ease of use \\
\hline Having a team table & 6.01 & 6.12 & 6.26 \\
\hline $\begin{array}{l}\text { Using wall surfaces that can support } \\
\text { image projections and annotations }\end{array}$ & 5.75 & 5.89 & 6.33 \\
\hline Using computers supplied by the college & 5.73 & 5.82 & 6.11 \\
\hline $\begin{array}{l}\text { Connecting computers, tablets or other } \\
\text { student-owned devices to the team } \\
\text { projector }\end{array}$ & 5.58 & 5.67 & 6.00 \\
\hline $\begin{array}{l}\text { Annotating projection surfaces while } \\
\text { working in teams }\end{array}$ & 5.35 & 5.5 & 5.88 \\
\hline $\begin{array}{l}\text { Sharing the work of a particular team with } \\
\text { the other teams }\end{array}$ & 5.07 & 5.23 & 5.35 \\
\hline $\begin{array}{l}\text { Capturing and sharing the image of a page } \\
\text { or a real object }\end{array}$ & 4.80 & 4.85 & 5.05 \\
\hline $\begin{array}{l}\text { Capturing an image of the team work on } \\
\text { the team surface }\end{array}$ & 4.53 & 4.68 & 5.07 \\
\hline Using tablets supplied by the college & 4.48 & 4.46 & 4.94 \\
\hline
\end{tabular}

Geogebra in math) was also highlighted in six comments. The importance of team tables and team wall surfaces was confirmed. Three students also mentioned table colors as an important feature in the classroom layout (in one classroom, each team had a table and wallboard of a different color).

In the three focus groups, the students also insisted on the importance of comfortable and easy to move chairs. This was the
TABLE 2 | Correlation between frequency of use, interest, utility and ease of use.

\begin{tabular}{lllll}
\hline & $\begin{array}{l}\text { Frequency } \\
\text { of Use }\end{array}$ & Interest & Usefulness & Ease of use \\
\hline Frequency of Use & 1 & $0.48^{\star}$ & $0.44^{\star}$ & $0.42^{\star}$ \\
Interest & $0.48^{\star}$ & 1 & $0.89^{\star}$ & $0.72^{\star}$ \\
Usefulness & $0.44^{\star}$ & $0.89^{\star}$ & 1 & $0.75^{\star}$ \\
Ease of Use & $0.42^{\star}$ & $0.72^{\star}$ & $0.75^{\star}$ & 1 \\
\hline
\end{tabular}

${ }^{*} p<0.001$

first and most important category that emerged from the group interview analysis.

It's better on the comfort side. Also, if you want to listen to or work with someone else, you do not have to drag a chair making noise. You just have to roll. (case 1-7)

I think the chair changes a lot of things. I can be at ease and comfortable. When I'm at ease, I am more able to listen. On plastic chairs, you have to sit very straight and you're always moving. With this other chair, we feel well and when we feel well, we can concentrate. It may sound silly, but just being able to move the chair up a little is very handy when someone ahead is blocking your view. (case 1-8)

I really feel it when I have another three-hour course: I have back pain afterwards. On these seats, three hours passes really quickly. Case 3-12 (R2) 


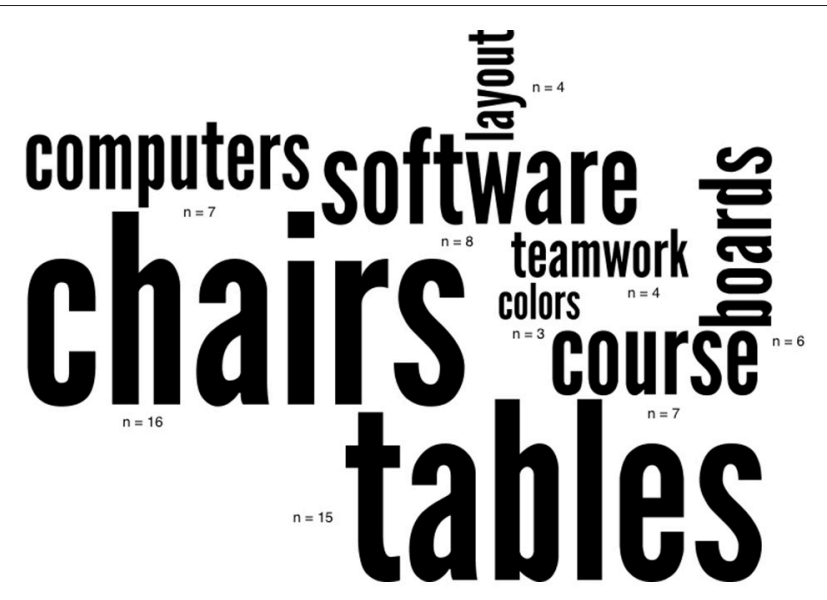

FIGURE 3 | Word cloud generated by a text analysis of 99 open-ended answers.

The second most important qualitative category that emerged from the group interviews (for the part of the interview focused on classroom layout) was a general category related to the special look and feel of the ALC, and the type of "atmosphere" or "climate" it generated.

With the atmosphere of this classroom, we are more relaxed than in a normal class. With a lower stress level, you think better and you are more productive...

I like how this class is arranged. It's good. We're comfortable and when the teacher walks around, we just have to rotate our chairs to follow him easily. Not always staying still helps me to focus. It's so different from other classes: the atmosphere is really better. (case 2-8)

I feel it's more welcoming. When you say wooden chair and small individual desk, I think of an exam, that's it. Here it is more familyfriendly kind of space. It's like when you go for dinner... at home we have dinner as a family and we talk to each other. It's nice and not stressful. (case 2-11)

In these group interviews, the students also pinpointed some of the challenges in the ALC set-up. The main challenge that emerged from these interviews is being able to see and hear when the teacher is lecturing. The fact that some students are sitting with their back to the teacher or that the teacher moves around frequently are common problems.

If a teacher wants to lecture, it has to be short. When you are at the other end of the class and you try to listen, you see the little PowerPoint or you have to turn towards the other table and then you lose eye contact and you are not focused. If I can't see the teacher talking, I can't see what is being written on the board. (case 3-10)

For some, the problem is more related to being able to see the teacher than the actual content.
It's more the vision that is problematic. I'm often sitting near the wall and the wall board, the third one down, so I cannot see what the teacher is writing. (case 2-9)

Several students of one particular focus group suggested a more flexible layout in the ALC.

For active learning tasks like this, I would rather have a traditional classroom layout with separate desks. When we are working on an active learning tasks, we would only have to move the desks together. (case 2-10)

\section{DISCUSSION}

These results confirm that from the students' point of view, the most important features of an ALC essentially support collaboration within the work environment-round tables, wall projection surfaces-a finding in line with Soneral and Wyse (2017). The importance of supplying very comfortable rolling chairs was the main finding in the qualitative data. The most expensive feature, requiring specific, costly hardware (Sharing the work of a particular team with the other teams), ranked among the lowest.

The fact that round tables are used in every class or many times during every class is not surprising, because classroom layout deeply influences the pedagogy that takes place (Brooks, 2012), but it also ranked first in terms of perceived utility, perceived interest and perceived ease of use.

\section{ALC Technological Environment: Computers and Tablets}

The fact that computers supplied by the institution ranked quite high is somewhat puzzling, given that over $90 \%$ of college students in Quebec owned a personal laptop in 2011 (Poellhuber and Karsenti, 2012) and that these numbers probably rose. In that earlier study, however, it was found that $<50 \%$ of students actually brought their computer to the college, for a variety of reasons: fear of theft or accidents and the fact that many teachers actually forbid the use of laptops in their classrooms.

In the tested ALC, one or two computers connected to the projector were available to each team. These computers were easy to connect and were loaded with a variety of software. This result suggests that in planning BYOD approaches, it is still useful to plan to supply a computer or tablet for each team pod.

There is an apparent contradiction in the results concerning tablets supplied by the institutions. Tablets were actually supplied in one of the participating colleges, but no teachers from that particular college took part in the study in the fall 2015 semester. While the frequency of use is very low, the perceived utility or interest of supplying tablets is rated quite high, which is consistent with the result concerning supplying computers.

\section{Relationship Between Ease of Use, Utility and Actual Use in the TAM Model}

The connection between ease of use and perceived utility or perceived interest is quite obvious in the correlation tables, so when developing an ALC, the administration should work on 
both ends: facilitate the use of functions that are less easy to use in order to increase their perceived utility and demonstrate the potential of particular functions in order to increase the students' interest.

From the TAM perspective, in this particular study, the interest component added little, if any, value to the model, since the interest and utility scores were almost identical for all functions. Deeper reflection is required on the links between ease of use and perceived utility. This relationship is already predicted by the TAM but more research could elucidate the process underlying the relationship (e.g., Ease of use Perceived utility or Perceived interest Ease of use), through structural equation modeling, for example (Park, 2009).

\section{Access to Specialized Software}

Sharing the screen of a particular team with the whole class is less easy to use than many other features and it is currently done by the teachers themselves, but our observations of class dynamics tend to show that physical proximity is an important vector for inter-team collaboration and sharing.

The relevance of subject-specific software was raised in the students' qualitative comments. The computers supplied by the institution came with pre-installed programs, which are sometimes quite expensive. This converges with other research results in the same project which indicate that the development of subject-specific technopedagogical knowledge is linked to student outcomes (St-Laurent, Poellhuber et al., submitted).

\section{ALC Set-Up}

The other salient qualitative category pertains to the special look and feel of the ALC. From the end-users' perspective (students), being in a space that conveys a different kind of atmosphere than a regular classroom seems to contribute to their intellectual and affective comfort, and even their engagement in group activities. This result is similar to what Park and Choi (2014) report: "Students perceived the ALC environment as more inspirational" (p. 749). While exploratory, this result suggests that special attention should also be placed on the esteem function in the functional analysis approach.

Some negative aspects of the ALC set-up also came up in the student group interviews. Many students reported problems when the teacher lectures, mainly related to the difficulty of seeing the teacher clearly and making eye contact or seeing the board the teacher is using (Park and Choi, 2014). Some students suggested a flexible approach to classroom layout rather than a fixed ALC layout. These comments support the flexibility concept which is present in many ALC layouts. Minor changes could also be made in order to make the teacher and the board more visible during lectures. The teacher podium could be shifted away from the center and toward the front and/or a slightly elevated podium could be built for the teacher. Half-rounded tables on wheels could also be used to easily recreate or dissolve the teams.

\section{Cost-Effective Planning of an ALC}

These results are good news for institutions that want to invest in ALC, because the most important features of an effective ALC can be designed and implemented at a fairly low cost. The results of Table 1 offer guidelines for an efficient cost/benefit ALC design. For example, some interesting devices linked to the teacher's computer can project the image of a real object. This type of equipment proved useful in this project because the teachers could easily show a variety of objects (manipulate valuable objects, show a newspaper article, show a problem taken from a book), adding spontaneity and personalization to their presentations. Solutions for this function run anywhere from $\$ 100$ to a few thousand dollars. Results show that investing a little money to supply one computer per table, loaded with relevant subject-specific software, might also be a good investment.

A traditional classroom with an even floor can be quickly flipped into a basic ALC by adding boards on the walls (approx. \$400 each) and grouping individual desks together to accommodate six students. Colour-coded floor stickers can be used to identify the best locations for the desks, should another user move them (\$6 per team). More permanent measures (attaching the desks) or a formal agreement between the users of the classroom is another option.

\section{LIMITS}

In terms of its limits, this study used single items to measure concepts, an approach that is not mainstream and that is still criticized by some researchers. A social desirability effect is probable, even though the students were reassured that their answers were anonymous.

The value of the TAM for predicting the adoption of particular features by students is also subject to debate. The fact that they use a particular function might be decided more by the instructor's pedagogical scenario than by the students' choice. In some cases, however, it is more likely a joint decision or even a team decision, where for some parts of the work, the team is free to determine which particular tool or function is used. The lower correlation between frequency of use and interest or utility supports this interpretation. A clearer portrait would draw on both teacher and student perceptions and would specify which aspects of use are determined by the teacher's choices and which are determined by the students'. Another limit of this study is that it did not investigate the way each function was mobilized in various pedagogical scenarios. The complex relationship between pedagogy and classroom layout is worthy of future investigation.

One limit of the functional analysis approach is that the particular way a function is made available to users may vary widely as far as ease of use is concerned. If a function is not perceived as easy to use, users will be less likely to use it and will not perceive its potential value. Future research could examine this using the concepts of affordance to investigate how users perceive the educational affordances offered in their environment and how they interact with these possibilities, using, for example, Gibson's ecological approach (John and Sutherland, 2005).

\section{CONCLUSION}

This study used a functional analysis approach to identify and prioritize the most important functions of an active learning 
classroom as linked to actual use by both teachers and learners. This approach offers design teams a high degree of freedom in the choice of how each function will actually be offered.

The most important functions are those can be achieved at moderate cost: the physical layout of the class (tables and chairs), wall boards, the ability to project an image from a device and to annotate that projection, etc. These results can be used to plan the development of active learning spaces in a way that ensures their features will be not only be usable, but actually used. This study clearly conveys the students' point of view on the desired layout of an ALC. From their perspective, planning for some flexibility seems important.

The use of the technology acceptance model was valuable for finding indicators of perceived ease of use, utility and interest that ranked similarly to frequency of use. This similarity suggests that students see the utility of the equipment used in class. Ease of use also points to solutions that could be improved in the future.

Future functional analysis approaches include comfortable chairs, esteem functions and some flexibility. Future studies could therefore explore the differences in the particular ways different functions are offered and draw on both student and teacher perceptions.

While this particular paper focused on ALC design, the whole study examined the sound pedagogical practices that take places in these environments and how to prepare and accompany teachers in adopting them. Planning the design of an ALC is important but it must go hand in hand with the instructors' preparations. The complex relationship between the teachers'

\section{REFERENCES}

Adams Becker, S., Cummins, M., Davis, A., Freeman, A., Hall Giesinger, C., and Ananthanarayanan, V. (2017). NMC Horizon Report: 2017 Higher Education Edition. Austin, TX: The New Media Consortium.

Alphonse-Prescott, A. (2016). The Physical Learning Environment of Online Graduate Students. Nova Southeastern University.

Anderson, T. (2005). Design-based research and its application to a call centre innovation in distance education. Can. J. Learn. Technol. 31. doi: $10.21432 / \mathrm{t} 26 \mathrm{k} 60$

Barrette, C. (2009). Métarecherche sur les effets de l'intégration des TIC en pédagogie collégiale. Revue internationale des technologies en pédagogie universitaire/Int. J. Technol. Higher Educ. 6, 18-25. doi: 10.7202/1000008ar

Basque, J. (2004). En quoi les TIC changent-elles les pratiques d'ingénierie pédagogique du professeur d'université? Int. J. Technol. Higher Educ. 1, 7-13. doi: 10.18162/ritpu.2004.52

Beichner, R. J., and Saul, J. (1999). "Student-centered activities for large-enrolment university physics (SCALE-UP)," in Proceedings of the Sigma Xi Forum on the Reform of Undergraduate Education (Minneapolis, MN), 43-52.

Beichner, R. J., Saul, J. M., Abbott, D. S., Morse, J. J., Duane, L., Allain, R. J., et al. (2007). "Research-based reform of university physics," in Physics, ed E. Redish and P. Cooney (College Park, MD: American Association of Physics Teachers), $1-42$.

Benoit, A. (2017). Monitoring implementation of active learning classrooms at lethbridge college. 2014-2015. J. Learn. Spaces 6, 14-25. Available online at: http://libjournal.uncg.edu/jls/article/view/1417

Bocconi, S., Kampylis, P., and Punie, Y. (2013). Framing ICT-enabled Innovation for Learning: the case of one-to-one learning initiatives in Europe. Eur. J. Educ. 48, 113-130. doi: 10.1111/ejed.12021

Brooks, D. C. (2011). Space matters: the impact of formal learning environments on student learning: impact of formal learning pedagogical practices, the physical layout and the technology, on one hand, and the students' motivation and engagement, on the other, should be investigated differently. For example, to gain a better understanding of the decisions to use or not use a particular function that is available in the classroom, a qualitative study could be undertaken to establish the relationship between the uses related to teachers' pedagogical scenarios and the uses developed by student teams.

\section{AUTHOR CONTRIBUTIONS}

$\mathrm{BP}$ was the main investigator in the research project and designed all aspects of the study, supervising the research at each point. $\mathrm{He}$ also wrote the largest part of the article. SF a doctoral student of BP was the co-researcher in the project. He supervised all data collection and participated in the research design. He helped plan the article at a high level and helped validate parts of the text. NR's contribution came at the analysis and article production phase. He conducted many statistical analyses, only a few of which are reported in this particular article. He contributed to the literature review and helped write the methods, results and discussion.

\section{ACKNOWLEDGMENTS}

This study was financially supported by an SSHRC partnership development grant (grant number 890-20120052), as well as a grant from the PAREA program of the Quebec Ministry of Education (PA2013-012). environments on student learning. Br. J. Educ. Technol. 42, 719-726. doi: 10.1111/j.1467-8535.2010.01098.x

Brooks, D. C., and Solheim, C. A. (2014). Pedagogy matters, too: the impact of adapting teaching approaches to formal learning environments on student learning. New Direct. Teach. Learn. 2014, 53-61. doi: 10.1002/tl. 20085

Brooks, D. D. (2012). Space and consequences: the impact of different formal learning spaces on instructor and student behavior. J. Learn. Spaces 1. Available online at: http://www.partnershipsjournal.org/index.php/jls/article/view/285

Brown, A. L. (1992) Design experiments: theoretical and methodological challenges in creating complex interventions in classroom settings. J. Learn. Sci. 2, 141-178. doi: 10.1207/s15327809jls0202_2

Carnell, B. S. (2017). Connecting physical university spaces with research-based education strategy. J. Learn. Spaces 6, 1-12. Available online at: http://discovery. ucl.ac.uk/1561146/

Charles, E. S., Lasry, N., and Whittaker, C. (2011). Scaling Up Socio-Technological Pedagogies. PAREA Research Report.

Chalgoumi (2011). Balises Pour l'Intervention Avec les Technologies Auprès des Élèves Qui ont des Incapacités Intellectuelles. Thesis, Montréal, QC: Université de Montréal.

Collins, A., Joseph, D., and Bielaczyc, K. (2004). Design research: theoretical and methodological issues. J. Learn. Sci. 13, 15-42. doi: 10.1207/s15327809jls1301_2

Cotner, S., Loper, J., Walker, J. D., and Brooks, D. C. (2013). “It's Not You, It's the Room"-Are the High-Tech, Active Learning Classrooms Worth It? J. Coll. Sci. Teach. 42, 82-88. doi: 10.2505/4/jcst13_042_06_82

Davis, F. D., Bagozzi R. P., and Warshaw, P. R. (1989). User acceptance of computer technology: a comparison of two theoretical models. Manage. Sci. 35, 982-1003. doi: $10.1287 / \mathrm{mnsc} .35 .8 .982$

Davis, F. D. (1989). Perceived usefulness, perceived ease of use, and user acceptance of information technology. MIS Q. 13, 319-340. doi: 10.2307/2 49008 
Dori, Y. J., Belcher, J., Bessette, M., Danziger, M., McKinney, A., and Hult, E. (2003). Technology for active learning. Mater. Today 6, 44-49. doi: 10.1016/S1369-7021(03)01225-2

Eccles, J. S., and Wigfield, A. (2002). Motivational beliefs, values, and goals. Annu. Rev. Psychol. 53, 109-132. doi: 10.1146/annurev.psych.53.100901.1 35153

Ha, I., Yoon, Y., and Choi, M. (2007). Determinants of adoption of mobile games under mobile broadband wireless access environment. Inform. Manage. 44, 276-286. doi: 10.1016/j.im.2007.01.001

Hake, R. R. (1998). Interactive-engagement versus traditional methods: a sixthousand-student survey of mechanics test data for introductory physics courses. Am. J. Phys. 66, 64-74. doi: 10.1119/1.18809

Hestenes, D., Wells, M., and Swackhamer, G. (1992). Force concept inventory. Phys. Teacher 30, 141-158.

Hoeppner, B. B., Kelly, J. F., Urbanoski, K. A., and Slaymaker, V. (2011). Comparative utility of a single-item versus multiple-item measure of selfefficacy in predicting relapse among young adults. J. Subst. Abuse Treat. 41, 305-312. doi: 10.1016/j.jsat.2011.04.005

John, P., and Sutherland, R. (2005). Affordance, opportunity and the pedagogical implications of ICT. Educ. Rev. 57, 405-413. doi: 10.1080/00131910500278256

Leung, S. O., and Xu, M. L. (2013). Single-item measures for subjective academic performance, self-esteem, and socioeconomic status. J. Soc. Serv. Res. 39, 511-520. doi: 10.1080/01488376.2013.794757

McGowan, B. S., Wasko, M., Vartabedian, B. S., Miller, R. S., Freiherr, D. D., and Abdolrasulnia, M. (2012). Understanding the factors that influence the adoption and meaningful use of social media by physicians to share medical information. J. Med. Int. Res. 14:e117. doi: 10.2196/jmir.2138

Miles, M. B., Huberman, A. M., and Saldana, J. (2013). Qualitative Data Analysis. Thousand Oaks, CA: Sage.

Park, E. L., and Choi, B. K. (2014). Transformation of classroom spaces: traditional versus active learning classroom in colleges. High. Educ. 68, 749-771. doi: 10.1007/s10734-014-9742-0

Park, S. Y. (2009). An analysis of the technology acceptance model in understanding university students' behavioral intention to use e-learning. J. Educ. Technol. Soc. 12, 150-162.

Pintrich, P. R. (2003). "Motivation and classroom learning," in Handbook of Psychology, Vol. 7, Educational Psychology, eds W. M. Reynolds and G. E. Miller (Hoboken, NJ: John Wiley \& Sons), 103-122.

Poellhuber, B., Duclos, A.-M., Fournier St-Laurent, S., and Moukhachen, M. (2018). Avantages et défis des classes d'apprentissage actif au collégial selon les enseignants et les étudiants : les résultats d'une première itération d'une recherche de type « design-based 》. Formation et Profession 26, 7-25. doi: 10.18162/fp.2018.387

Poellhuber, B., and Karsenti, T. (2012). Les Habitudes Technologiques au Cégep: Résultats d'une Enquête Effectuée Auprès de 30724 Étudiants. Research Report. Montréal, QC: Centre de recherche interuniversitaire sur la formation et la profession enseignante (CRIFPE).

Poellhuber, B., Roy, N., and Duclos, A.-M. (2013). A Mixed Methods Analysis of Closed-Gate Academic Social Network Usages Based on the TAM Model. San Francisco, CA: Dans Actes du colloque de l'AERA.

Rocque, S., Langevin, J., and Riopel, D. (1998). L'analyse de la valeur pédagogique au Canada: méthodologie de développement de produits pédagogiques. $\mathrm{La}$ valeur des produits, procédés et services 76, 6-11.
Roland, N., and Talbot, L. (2015). L'environnement personnel d'apprentissage : un système hybride dinstruments, 21. Available online at: http://sticef.univ-lemans. $\mathrm{fr} / \mathrm{num} / \mathrm{vol} 2014 / 20$-roland-epa/sticef_2014_NS_roland_20.htm

Severin, P. P. (2009). L'analyse Fonctionnelle, de la Méthode aux outils Course Handouts from the Course "Biotechnologies Santé Environnement." Lycée des métiers de l'hôtellerie et du tourisme de Toulouse. Available online at: http:// asset.free.fr/IMG/pdf/Analyse_fonctionnel_complet_pub.pdf

Soneral, P. A., and Wyse, S. A. (2017). A SCALE-UP mock-up: comparison of student learning gains in high- and low-tech active-learning environments. Cell Biol. Educ. 16:ar12. doi: 10.1187/cbe.16-07-0228

St-Laurent, S. F., Poellhuber, B., and Moukhachen, M. (2017). Liens entre le modèle CBAM et l'approche d'enseignement dans le contexte de l'adoption d'une classe d'apprentissage actif par des enseignants au postsecondaire| Relationships between the CBAM Model and the approach to teaching inventory in the adoption of the active learning classrooms by postsecondary teachers. Can. J. Learn. Technology/La Revue Canadienne de l'apprentissage et de La Technologie, 42. doi: 10.21432/T2S32X.Available online at: http://www.cjlt.ca/index.php/ cjlt/article/view/27528/20234

Stoltzfus, J. R., and Libarkin, J. (2016). Does the room matter? active learning in traditional and enhanced lecture spaces. CBE Life Sci. Educ. 15, ar68. doi: $10.1187 /$ cbe.16-03-0126

Venkatesh, V., and Davis, F. D. (1996). A model of the antecedents of perceived ease of use: Development and test. Dec. Sci. 27, 451-481. doi: 10.1111/j.1540-5915.1996.tb01822.x

Vo, N. T. B. (2015). College Students' Choice of Informal Learning Spaces. Columbia: Doctoral dissertation, University of Missouri.

Wanous, J. P., Reichers, A. E., and Hudy, M. J. (1997). Overall job satisfaction: how good are single-item measures?. 82, 247-252.doi:10.1037/0021-9010.82.2.247

Wesch, M. (2007). A Vision of Students Today. Available online at: https://www. youtube.com/watch?v=dGCJ46vyR9o

Whiteside, A., Brooks, D. C., and Walker, J. D. (2010). Making the Case for Space: Three Years of Empirical Research on Learning Environments. EDUCAUSE Quarterly. Available online at: http://www.educause.edu/ero/article/makingcase-space-three-years-empirical-research-learning-environments

Wilson, H. K., and Cotgrave, A. J. (2016). Factors that influence students' satisfaction with their physical learning environments. Struct. Survey 34, 256-275. doi: 10.1108/ss-01-2016-0004

Woolner, P., McCarter, S., Wall, K., and Higgins, S. (2012). Changed learning through changed space: when can a participatory approach to the learning environment challenge preconceptions and alter practice? Improving Sch. 15, 45-60. doi: 10.1177/1365480211434796

Conflict of Interest Statement: The authors declare that the research was conducted in the absence of any commercial or financial relationships that could be construed as a potential conflict of interest.

Copyright (c) 2018 Poellhuber, Fournier St-Laurent and Roy. This is an open-access article distributed under the terms of the Creative Commons Attribution License (CC $B Y)$. The use, distribution or reproduction in other forums is permitted, provided the original author(s) and the copyright owner are credited and that the original publication in this journal is cited, in accordance with accepted academic practice. No use, distribution or reproduction is permitted which does not comply with these terms. 